\title{
Modification of Yttrium-Stabilized Zirconia Ceramics Using Calcium Phosphate
}

\author{
Myung Chul Chang ${ }^{\dagger}$ \\ Department of Materials Science and Engineering, Kunsan National University, Kunsan 573-701, Korea
}

(Received June 6, 2013; Revised July 5, July 16, 2013; Accepted July 17, 2013)

\begin{abstract}
A biomimetic approach was applied for the chemical deposition of calcium phosphate (CaP) coatings on 3 mole\% yttrium-stabilized zirconia [3YSZ] powders. The solid-state reaction of 3YSZ powders with the addition of CaP was investigated for the development of biodegradable zirconia ceramics. The solid-state interaction between the 3YSZ matrix powders and the CaP additives differed from the behavior of commercial zirconia matrix powders. The 3YSZ powders were chemically reacted with precursors for the $\mathrm{CaP}$ formation. 3YSZ powders were mixed in an aqueous solution of $\mathrm{Ca}-\mathrm{P}$ precursors and the $\mathrm{CaP}$ was precipitated on the surface of the $3 \mathrm{YSZ}$ matrix powders. The CaP-doped YSZ powders were calcined at $1100^{\circ} \mathrm{C}$ and shaped powder blocks were then fired at $1600^{\circ} \mathrm{C}$ for $2 \mathrm{~h}$. The $\mathrm{CaP}$ phase formation was investigated using FE-SEM and XRD analysis.
\end{abstract}

Key words : Calcium phosphate, Zirconia, Solid-state interaction

\section{Introduction}

$\mathrm{Y}$ ttrium-stabilized zirconia (YSZ) has been used as a dental laminate material due to its good mechanical properties, biocompatibility, and for patient-oriented esthetic reasons. Zirconia is bioinert, and this leads to the poor fixation of a ceramic implant in the bone. The incorporation of $\mathrm{CaP}$ into the zirconia matrix has been attempted in an effort to determine if the controlled release of calcium and phosphate ions can have an osteoinductive effect..$^{1-3)}$ For an implant application, the biodegradable modification of YSZ ceramics has been investigated; the incorporation $\mathrm{CaP}$ into the zirconia matrix can potentially increase the osteoinductivity of the scaffold and therefore promote osteogenesis when implanted in vivo. ${ }^{4-6)}$ Zirconia powders are coated with thin layers of calcium phosphate $(\mathrm{CaP})$, which is known to be bioactive and osteoconductive, leading to good bone-bonding ability and support bone-tissue in-growth. ${ }^{7-9)}$ Hydroxyapatite (HAP) and $\beta$-tricalcium phosphate ( $\beta$-TCP) ceramics have been used in the development of bone scaffolds and have been shown to increase the levels of osteoconductivity (support cell attachment). Calcium and phosphate ions have been postulated to be osteogenic factors that enhance osteoblast differentiation and mineralization.

The aim has been a combination of the excellent mechanical properties (toughness, wear resistance) of CaPcoated zirconia with the biocompatibility and osteocon-

${ }^{\dagger}$ Corresponding author: Myung Chul Chang

E-mail : mcchang@kunsan.ac.kr

Tel : +82-63-469-4735 Fax : +82-63-469-4731 ductive potential of CaP. These applications have involved the use of nano-metric or micrometric-sized zirconia and CaP powders obtained by wet precipitation methods. Stabilized zirconia is most commonly formed by pressing and sintering at temperatures ranging from $1300^{\circ} \mathrm{C}$ to $1600^{\circ} \mathrm{C}$. The selected sintering temperature must be kept as low as possible because $\mathrm{CaP}$ decomposes in $\beta$-tricalcium phosphate, $\left(\mathrm{Ca}_{3}\left(\mathrm{PO}_{4}\right)_{2}\right) \mathrm{TCP}$, at temperatures higher than $1000^{\circ} \mathrm{C}$. This process affected with the ratio of the $\mathrm{CaP}$ addition into the YSZ matrix, through a reaction between both phases. In this report, a solid-state reaction between YSZ powders and $\mathrm{CaP}$ additives was investigated using commercially well-known zirconia powders and a dental block.

\section{Experimental Procedure}

\subsection{Sample Preparation}

As YSZ matrix commercial powders, KZF-3Y (Kyoritz, Japan) and TZ-3Y (Tosoh, Japan) were used. The precursors for the $\mathrm{CaP}$ formation were $\mathrm{MgCl}_{2} \cdot \mathrm{H}_{2} \mathrm{O}$ (Hayashi), $\mathrm{CaCl}_{2}$ (Aldrich), and $\mathrm{Na}_{3} \mathrm{PO}_{4}$ (TSP, Aldrich). On the basis of the YSZ matrix, the amounts of precursors were calculated for the formation of octacalcium phosphate (OCP) or tricalcium phosphate [TCP] powders. In these experimental calculations, the total amount of YSZ matrix with $\mathrm{CaP}$ additives was based on $10 \mathrm{~g}$ batches.

The chemical reactions for the formation of calcium phosphate $(\mathrm{CaP})$ can be written as follows:

$$
\begin{aligned}
& \mathrm{MgCl}_{2} \cdot 6 \mathrm{H}_{2} \mathrm{O}+\mathrm{TZ}-3 \mathrm{Y}(\mathrm{s}) \rightarrow \mathrm{YSZ}-\mathrm{Mg}(\mathrm{OH})_{2}+\mathrm{Cl}^{-}+\mathrm{H}^{+} \\
& 2 \mathrm{Mg}^{2+}+\mathrm{PO}_{4}^{3-}+\mathrm{H}^{+}+\mathrm{OH}^{-} \rightarrow \mathrm{MgHPO}_{4}+\mathrm{Mg}(\mathrm{OH})_{2}
\end{aligned}
$$




$$
\begin{aligned}
& 3 \mathrm{CaCl}_{2}(\mathrm{aq})+2 \mathrm{Na}_{3} \mathrm{PO}_{4}(\mathrm{aq}) \rightarrow \mathrm{Ca}_{3}\left(\mathrm{PO}_{4}\right)_{2}(\mathrm{~s}) \downarrow+6 \mathrm{NaCl}(\mathrm{aq}) \\
& 3 \mathrm{CaCl}_{2} \cdot 2 \mathrm{H}_{2} \mathrm{O}+2 \mathrm{Na}_{3} \mathrm{PO}_{4}(\mathrm{aq}) \rightarrow \mathrm{TCP} \\
& 2 \mathrm{CaHPO}_{4}[\mathrm{DCPA}]+2 \mathrm{Ca}_{3}\left(\mathrm{PO}_{4}\right)_{2}[\mathrm{TCP}] \rightarrow \mathrm{OCP}
\end{aligned}
$$

In this experiment, the calculated amounts of zirconia matrix and OCP as an additive were $9.9242 \mathrm{~g}$ and $0.0758 \mathrm{~g}$, respectively. The OCP phase is formed through a solidstate reaction in a mixture of $2 \mathrm{DCPA}$ and TCP, as shown in Eq. (5). In order to make the OCP-modified YSZ ceramics, the calculated amounts of DCPA and TCP were $0.02338 \mathrm{~g}$ and $0.05433 \mathrm{~g}$, respectively. The respective amounts of $\mathrm{CaCl}_{2} \cdot 2 \mathrm{H}_{2} \mathrm{O}$ and $\mathrm{Na}_{3} \mathrm{PO}_{4}$ were $0.07725 \mathrm{~g}$ and $0.05743 \mathrm{~g}$ for the formation of $0.0543 \mathrm{~g}$ of TCP.

A small amount of $\mathrm{MgCl}_{2} \cdot 6 \mathrm{H}_{2} \mathrm{O}$, as shown in Fig. 1, was added to the zirconia powders of TZ-3Y or KZF-3Y and mixed in DI $\mathrm{H}_{2} \mathrm{O}$ while stirring for an hour to form $\mathrm{Mg}(\mathrm{OH})_{2}$, which would be attached onto the zirconia powders, as shown in Eq. 1. As expressed by Eq. 2, magnesium phosphate may be formed with an $\mathrm{Mg}(\mathrm{OH})_{2}$ layer on YSZ powder. The precipitation of CaP, i.e., TCP, HAP or OCP from the solution, is a base uptake process. The amount of zirconia matrix powder is $9.9242 \mathrm{~g}$, and the $3 \mathrm{YSZ}$ powders were stirred in a beaker with DI water for $1 \mathrm{~h}$. The respective amounts of tri-sodium phosphate (TSP) used here were $0.05743 \mathrm{~g}, 0.0678 \mathrm{~g}$ and $0.07758 \mathrm{~g}$ for $0.75 \mathrm{CaP}, 1.0 \mathrm{CaP}$ and $1.25 \mathrm{CaP}$ doping on YSZ powders. The TSP powders were dissolved in DI water while stirring and the aqueous solutions were dropped into an aqueous mixture of $\mathrm{CaCl}_{2}$ at $0.7725 \mathrm{~g}$, DCPA $\left(\mathrm{CaHPO}_{4}\right.$, dicalcium phosphate anhydrous) at $0.02338 \mathrm{~g}$ and $\mathrm{MgCl}_{2}$ at 0.007566 , which were preliminary stirred with zirconia matrix powders at $37^{\circ} \mathrm{C}$ for $30 \mathrm{~min}$. During the dropping of the TSP aqueous solutions, the mixture solution was stirred at $90^{\circ} \mathrm{C}$ to activate the TCP phase formation on the surface of the zirconia powders. The slurry mixture was settled down after the precipitation of TCP and the DCPA powders were then added to the slurry solution while stirring. Normally, DCPA is not completely dissolved in water ${ }^{10)}$ and therefore some time is needed to ensure a clear mixture. DCPA is a mildly acidic and soluble (at the physiological $\mathrm{pH}$ ) calcium phosphate $(\mathrm{CaP})$ phase. The dissolution kinetics of $\mathrm{CaHPO}_{4}$ in water at $37^{\circ} \mathrm{C}^{11)}$ showed that $\mathrm{Ca}^{2+}$ and $\mathrm{HPO}_{4}^{2-}$ ions were initially released from the DCPA; this completely stopped after four days in contact with the water at $37^{\circ} \mathrm{C}$. The dissolution of DCPA is known to be incongruent, ${ }^{11)}$ which would be caused by the formation of a thin apatitic (apatite-like) calcium phosphate (HAp-CaP) layer on the surfaces of CaHPO4 particles through a topotactic reaction, which hindered further dissolution. Some self-hardening $\mathrm{CaP}$ pastes contain, for instance, approximately $25 \mathrm{wt} \%$ CaHPO4 in their powder components. After filtration and drying, a binder solution was added to the powders. In order to make the binder solution, $0.2 \mathrm{~g}$ of PVA and $0.1 \mathrm{~g}$ of glycerin were dissolved in $10 \mathrm{~mL} \mathrm{DI} \mathrm{H}_{2} \mathrm{O}$. The shaped sample body was fired at $1550^{\circ} \mathrm{C}$ or

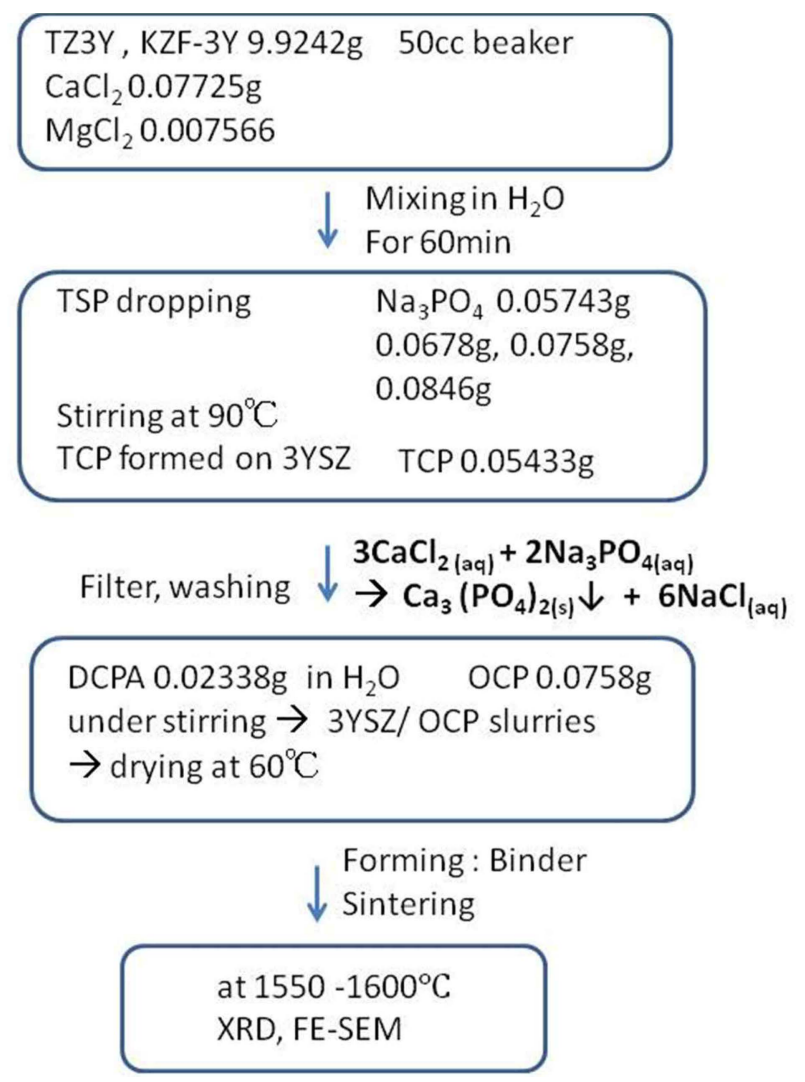

Fig. 1. Flow diagram of the precipitation of calcium phosphate into the zirconia powders. TZ-3Y and KZF-3Y were used.

\section{$1600^{\circ} \mathrm{C}$ for $2 \mathrm{~h}$.}

Figure 1 shows the $\mathrm{CaP}$ coating process for the zirconia powders. The assumed amounts of formed OCP and zirconia matrix were $0.0758 \mathrm{~g}$ and $9.9242 \mathrm{~g}$, respectively. Through the wet precipitation process, $0.07598 \mathrm{~g}$ of the OCP powders may be formed in the $9.9242 \mathrm{~g}$ of KZF-3Y zirconia powders. The aqueous binder solution was added to the mixed powders, and after drying, the hardened paste was ground by a pestle to be used for forming. The sample body was sintered at $1550^{\circ} \mathrm{C}$ or $1600^{\circ} \mathrm{C}$ for $2 \mathrm{~h}$. The precipitation condition was precisely controlled to obtain the YSZ powders, which were uniformly coated by $\mathrm{CaP}$ phase and $\mathrm{Mg}(\mathrm{OH})_{2}$. Through the wet precipitation method, the resulting CaP-doped YSZ ceramics showed a property change in terms of their density and microstructure. In particular, the microstructure of the CaP-doped YSZ ceramics was compared with that of a Prettau $^{\circledR}$ sample body, which is a well-known esthetic dental laminate material.

In dental applications, zirconia powders are shaped and fired at $1100-1200{ }^{\circ} \mathrm{C}$ to make the primary dental block. Normally, a commercially supplied dental block is machined in a dental laboratory using $\mathrm{CAD} / \mathrm{CAM}$ according to the patient-oriented tooth design, as required by the dentist. The machined block is fired at $1400-1600^{\circ} \mathrm{C}$ and the sintered zirconia block is finally polished and color-stained for the final tooth design. Prettau is commercially well-known 
as an esthetic zirconia implant material for use in dental applications. In this experiment, the supplied Prettau zirconia block was finally sintered at $1600^{\circ} \mathrm{C}$ for $2 \mathrm{~h}$. The Prettau block was used as a reference sample for the CaP-doped zirconia in the SEM microstructure and EDS analysis.

The CaP-precipitated YSZ powders were calcined at $675^{\circ} \mathrm{C}$, $750^{\circ} \mathrm{C}$ and $800^{\circ} \mathrm{C}$ for $2 \mathrm{~h}$ and were then cooled. The powders were uniaxially shaped under 5 tons of pressing. The samples were then sintered at $1600^{\circ} \mathrm{C}$ for $2 \mathrm{~h}$.

\subsection{Characterization}

The crystal phase was confirmed using X-Ray diffraction [Bruker, M18XCE] of the crushed powders. The microstructure of the CaP-doped YSZ ceramics was observed by means of FE-SEM [Hitachi, S-4800].

\section{Results and Discussion}

In the preparation of the CaP-doped 3YSZ powders and ceramics, the major crystals are tetragonal, and the monoclinic phase was partially developed for the YSZ samples calcined at $675-800{ }^{\circ} \mathrm{C}$. In Fig. 2, the XRD intensity of the monoclinic phase is shown to decrease with an increase in the calcining temperature.

In Fig. 3(a), the grain sizes of the TZ-3Y are $200-600 \mathrm{~nm}$ and $400-1200 \mathrm{~nm}$ for the samples sintered at $1550^{\circ} \mathrm{C}$ and $1600^{\circ} \mathrm{C}$, respectively. Figure $3(\mathrm{~b})$ shows the grain microstructure of the commercial dental block, Prettau, sintered at $1600{ }^{\circ} \mathrm{C}$. The microstructure in Fig. 3(b) is similar with that shown in Fig. 3(a), but it was noted that the dental block shows unique micro-grain growth during full densification at $1600^{\circ} \mathrm{C}$. The circled region in the expanded image in Fig. 3(b) shows the individual micro-grain growth in a grain. The arrows indicate the micro-grain boundary region, which moves with the micro-grain growth in the grain. It is noted in Table 1 that the Prettau sample, a typical esthetic zirconia block, has a considerable amount of CaP composition along the grain boundary region. In Table 1, the compo-

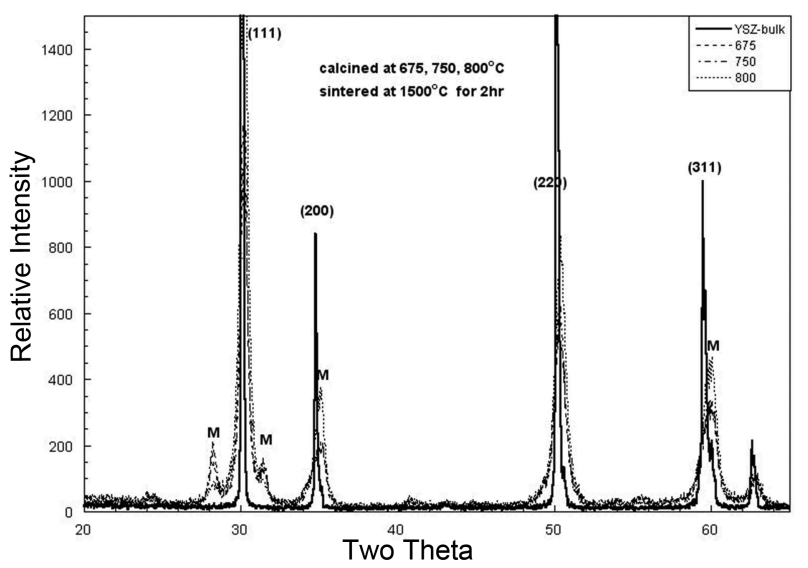

Fig. 2. X-ray diffraction patterns of the CaP-doped YSZ powders fired at $675,750,800$, and $1500^{\circ} \mathrm{C}$. sition was obtained by an EDS analysis of the sintered body. It is assumed that CaP-doped YSZ powders were used in the Prettau block and that the final grain growth was enhanced by the micro-grain growth, which arose from the powder granules during the sintering densification process. The CaP incorporation into the YSZ matrix may contribute to enhancing the grain boundary migration. From the internal microstructure morphology of a grain, it appears that the CaP phase was homogeneously coated on the YSZ matrix. In Fig. 3(b), the circled region shows the internal grain growth in a grain, in which a smaller grain boundary migrated to form a larger grain during the sintering process at $1600^{\circ} \mathrm{C}$. In fact, for a dental laminate application, the presintered block at $1100^{\circ} \mathrm{C}$ is machined using $\mathrm{CAD}$ and finally sintered at $1600{ }^{\circ} \mathrm{C}$. The requirements for the fired laminate sample are translucency and color to match those of the patient's teeth. From the above-mentioned results pertaining to TZ-3Y and Prettau samples, it is assumed that the commercial dental product Prettau was composed of CaPdoped 3YSZ powders, which induces bone-like behavior in terms of translucency and color.

Figure 4 shows the CaP-doped YSZ samples, specifically the 1.25 CaP TZ3Y and 1.0 CaP KZF-3Y samples, compared

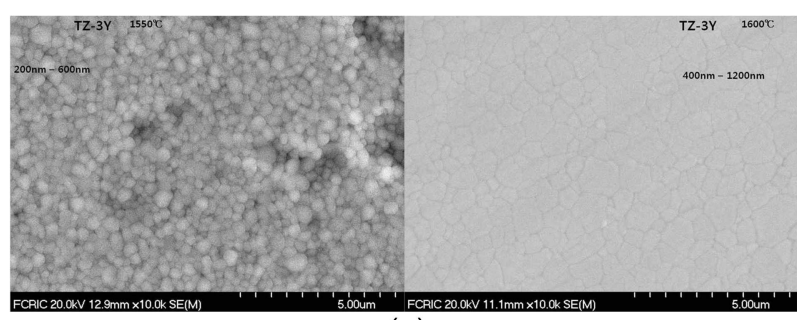

(a)

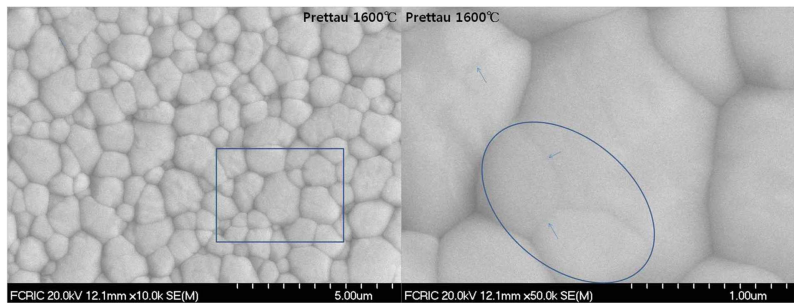

(b)

Fig. 3. FE-SEM photographs of YSZ ceramics: (a) TZ-3Y ceramics fired at $1550^{\circ} \mathrm{C}$ and $1600^{\circ} \mathrm{C}$, (b) Prettau ceramics fired at $1600^{\circ} \mathrm{C}$ showing internal grain growth.

Table 1. Compositions (wt\%), BET, and Translucency for the Samples of TZ-3Y, KZF-3Y-0, and Prettau.

\begin{tabular}{|c|c|c|c|}
\hline & TZ-3Y & KZF-3Y-0 & Prettau \\
\hline $\mathrm{ZrO} 2$ & 94.21 & 94.53 & 93.90 \\
\hline $\mathrm{Y} 2 \mathrm{O} 3$ & 5.21 & 5.47 & 5.423 \\
\hline $\mathrm{Al} 2 \mathrm{O} 3$ & 0.005 & 0.216 & 0.004 \\
\hline $\mathrm{Ca}, \mathrm{P}$ & & & Ca 0.374 P 0.393 \\
\hline $\mathrm{Mg}$ & & & Mg 0.015 \\
\hline BET(m2/g) & 14.8 & 12.9 & \\
\hline translucency & 7 & 7 & 10 \\
\hline
\end{tabular}




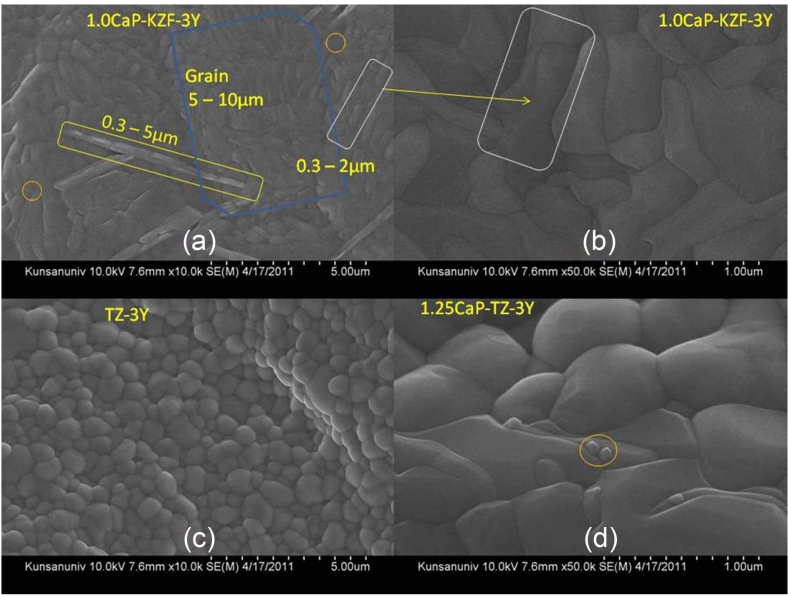

Fig. 4. FE-SEM microstructure for CaP-doped YSZ ceramics: (a) KZF-3Y_1.0 CaP/Mg, (b) KZF-3Y_1.0 CaP/Mg (c) TZ-3Y, and (d) TZ-3Y_1.25 CaP/Mg.

with the Prettau sample, in Fig. 3. The CaP-coated samples were sintered at $1600{ }^{\circ} \mathrm{C}$ for $2 \mathrm{~h}$. In Fig. 4(a) there are three types of morphology: long rectangles at $0.3 \mu \mathrm{m} \mathrm{W} \times 5 \mu \mathrm{m} \mathrm{L}$, small spheres with a $0.3 \mu \mathrm{m}$ diameter, and largely distorted rectangle shapes $0.3 \mu \mathrm{m} \mathrm{W} \times 2 \mu \mathrm{m} \mathrm{L}$ in size. The grain has the hexagonal shape, which is a combination of rectangular micro-grains. In Fig. 4(b), each grain is composed of an alignment of distorted rectangular micro-grains. Figure 4(c) shows a normal microstructure with sphere-like grains, as in TZ-3Y. In the 1.25 CaP-doped TZ-3Y ceramics in Fig. 4(d), the circled region shows small spheres in which the incorporation limit may lead to the formation of the $\mathrm{CaP}$ phase around the grain boundary. The grains show rounded rectangle-shaped grains and a few spheres. From the EDS analysis and the sintering densification process, the solid-state interaction between the zirconia matrix and the formed $\mathrm{CaP}$ was less effective in the TZ-3Y series, though it was very effective in KZF-3Y. As shown in Fig. 4, it was not easy to obtain a uniform grain morphology composed of rectangular micro-grains of the types which may be formed through the incorporation of $\mathrm{CaP}$ into the zirconia matrix region. In the 0.75 CaP-TZ-3Y samples, obtaining a uniform grain morphology composed of rectangular micro-grains was more difficult despite the fact that the amount of $\mathrm{CaP}$ added was considerably reduced. On the other hand, in the $1.0 \mathrm{CaP}$ doped KZF-3Y, the grain growth was uniformly distributed through a combination of internal, rectangular micrograins.

Figure 5 shows the EDS analysis results of three particular shapes in terms of their SEM microstructures. The EDS analysis in Fig. 5(b) for the parts labeled as 1, 2, and 3 shows the possible formation of the CaP phase. The 1.0 CaP doped KZF-3Y zirconia was sintered at $1600^{\circ} \mathrm{C}$ for $2 \mathrm{~h}$. In general, 3YSZ ceramic materials show uniformly developed spherical grain growth. CaP-doped KZF-3Y zirconia ceramics show versatile microstructures such as rectangular modified spheres (1), broad rectangles (2), and spheres (3). In

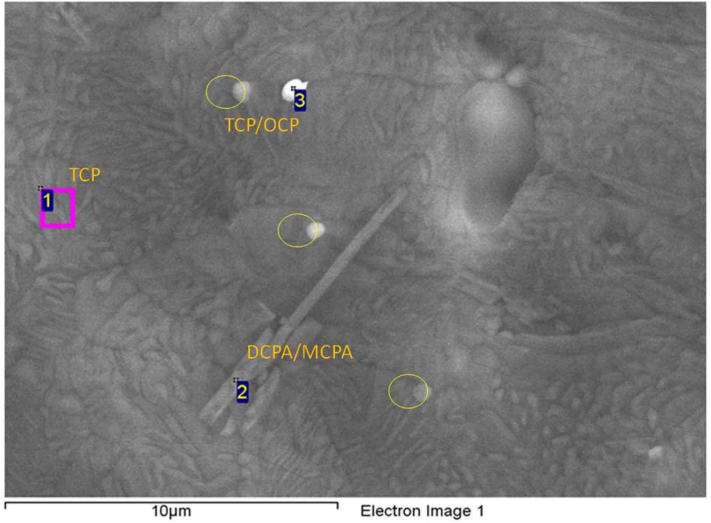

(a)

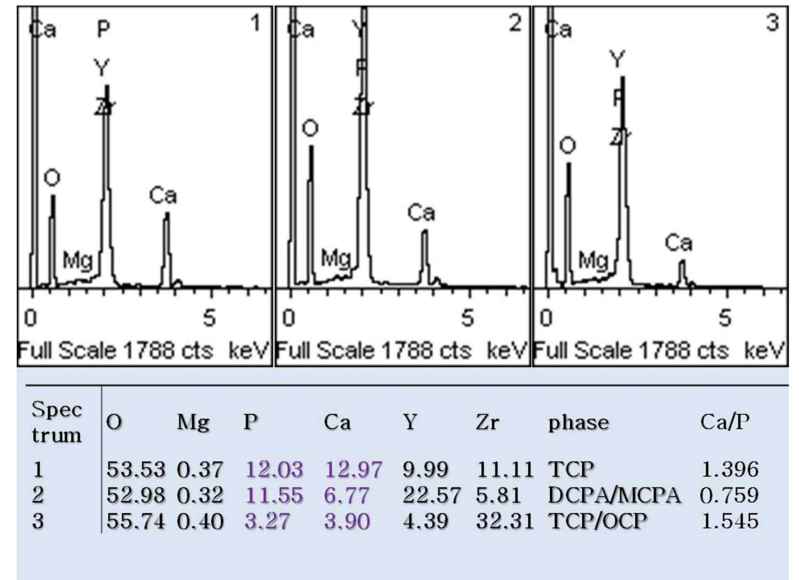

(b)

Fig. 5. EDS analysis of CaP-doped YSZ ceramics of KZF3Y_1.0 OCP/Mg.

sphere region 3 , the amount of $\mathrm{CaP}$ in the $3 \mathrm{YSZ}$ matrix is relatively low. With an increase of the incorporated $\mathrm{CaP}$ amount, the grain shape became broadly rectangular, as shown in region 2. From the EDS analysis, each region of differently shaped domains or grains is related to the degree of $\mathrm{CaP}$ incorporation into the YSZ particles. If an appropriate amount of $\mathrm{CaP}$ is chemically incorporated into the YSZ particles, the sintered body will show an entirely uniform microstructure.

TZ3Y is effective for the densification of zirconia ceramics and is feasible for use when shaping and sintering are required. The powder distribution quality is based on control of the particle size and granule formulation as prepared using a spray drier. Normally, the specified binder is left after spray drying, and this process is effective as a forming process using a hydrostatic press. However, for slip casting, the powders have to be uniformly distributed using a binder and a deflocculant for the dispersion of the zirconia suspension. In this research, we attempted to coat the surface of zirconia powders chemically. In the experiments, the CaP phase was formed on the as-received zirconia powders by a wet precipitation process. The sintering behavior was different in the TZ-3Yand KZF-3Y samples. The BET values $\left(\mathrm{m}^{2} / \mathrm{g}\right)$ 


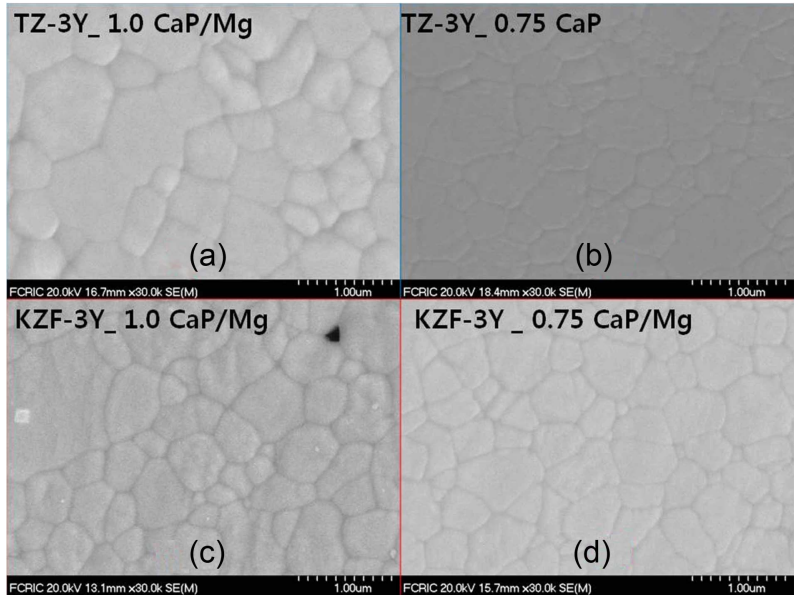

Fig. 6. FE-SEM microstructure for CaP-doped YSZ ceramics: (a) TZ-3Y_1.0 CaP/Mg (b) TZ-3Y_0.75 CaP/Mg (c) KZF-3Y_1.0 CaP/Mg, and (d) KZF-3Y_0.75 CaP/ $\mathrm{Mg}$.

of the primary particles in TZ-3Y and KZG-3Y were 14.8 and 12.9 , respectively.

The FE-SEM and EDS results may explain the solid-state reaction between the $\mathrm{CaP}$ and YSZ powders. The purpose of CaP coating onto the zirconia powders was to obtain highly dense zirconia ceramics without losing translucency while retaining a CaP layer, which would show good biocompatibility as a dental implant. From the EDS analysis results in Fig. 5, KZF-3Y showed good solid-state interaction with $\mathrm{CaP}$ at above $1550^{\circ} \mathrm{C}$ compared to that of TZ-3Y.

The sintered body of the CaP-doped TZ-3Y showed a decrease in the sintering density and a loss of translucency. KZF-3Y retained its good sintering density in this experimental CaP composition range. TZ-3Y was developed as an engineering zirconia ceramic having a good sintering ability; therefore, the powder granules are useful in a dry pressing process to make sample bodies. Normally in the sintering process, the sample body was formed by dry pressing using spray-dried powders. The firing process of the shaped body is controlled to burn off the remaining binder in the spray dry powders, with final sintering at $1150^{\circ} \mathrm{C}$ for several hours to make a zirconia block for CAD/ACM machining. The machined body is finally sintered at above $1550^{\circ} \mathrm{C}$ for several hours.

From the EDS analysis, the CaP doping in KZF-3Y matrix was very effective to show an esthetic color change and retain a feasible level of translucency. That is, as a zirconia matrix showing good solid-state interaction with CaP, KZF$3 \mathrm{Y}$ powder was more effective. We could control the amounts of $\mathrm{CaP}$, the $\mathrm{CaP}$ precursors, and other factors such as the $\mathrm{MgO}$ buffer layer. Fig. 5(b) shows the existence of the $\mathrm{Mg}$ composition excluding the $\mathrm{CaP}$ phase, indicating the $\mathrm{MgO}$ buffer layer. In TZ-3Y, CaP doping using the wet chemical process was less effective to show an esthetic color change and to retain the translucency. The Prettau sample shows the existence of the CaP composition from EDS data in Table 1, which corresponds to the OCP phase. In this research, the KZF-3Y is appropriate for the modification of zirconia powders using $\mathrm{CaP}$ precursors.

For the CaP-doped samples sintered at $1600^{\circ} \mathrm{C}$ for $2 \mathrm{~h}$, Fig. 6 it shows the microstructural change with the incorporation of $\mathrm{CaP}$ into the core grain around the grain boundary region. In Fig. 6(b) (d), the addition of $0.75 \mathrm{CaP}$ into the KZF-3Y and TZ-3Y samples resulted in a similar microstructure. In Fig. 6(a) (b), showing CaP-doped TZ-3Y, the grain size was increased considerably with the addition of CaP. However, in Fig. 6(c) (d), showing CaP-doped KZF-3Y, the microstructure was less changed in the $1.0 \mathrm{CaP} / \mathrm{Mg}$ samples. The microstructural homogeneity was investigated with the amount of $\mathrm{CaP} / \mathrm{Mg}$ ranging from 0.7 to 1.2 . Above 1.0, the sintering was not homogeneous and the density decreased. It is known ${ }^{7}$ that the existence of magnesium metaphosphate as an interlayer is very effective for the coating of $\beta$-tricalcium phosphate on yttria-stabilized zirconia. In the wet chemical process shown in Fig. 1, $\mathrm{Mg}(\mathrm{OH})_{2}$ and/or $\mathrm{Mg}$ phosphate buffer layers were formed on YSZ powders. The precursors of the $\mathrm{Ca}^{2+}$ and $\mathrm{PO}_{4}$ ions were mixed to make TCP and finally form the OCP phase on the YSZ powders. From this experiment, it is considered that $\mathrm{Mg}(\mathrm{OH})_{2}$ buffer layers exist on the YSZ powders and that some of the $\mathrm{Mg}(\mathrm{OH})_{2}$ buffer layers may react with $\mathrm{Ca}$ and phosphate ions. During the calcination and sintering process, the solid-state reaction may be affected by the $\mathrm{Mg}$ compound buffer layers.

\section{Conclusions}

The solid-state interaction between $\mathrm{CaP}$ and a zirconia matrix in 3YSZ ceramics was investigated. A CaP layer was chemically precipitated on nano-crystalline powders of 3YSZ. The solid-state interaction between the YSZ matrix powders and the $\mathrm{CaP}$ doping layer was different depending on the supplied commercial powder.

\section{Acknowledgment}

This research was supported by the general research support program of the National Research Foundation (NRF) funded by the Korean Government (NO. 10B10415111).

\section{REFERENCES}

1. C. Mansur, M. Pope, M. R. Pascucci, and S. Shivkumar, "Zirconia-Calcium Phosphate Composites for Bone Replacement," Ceram. Int., 24 [1] 11-9 (1998).

2. E. Zafer, U. Metin, and K. Isil, "Improvement in Sinterability and Phase Stability of Hydroxyapatite and Partially Stabilized Zirconia Composites," J. Eur. Ceram. Soc., 29 621-28 (2009).

3. B. M. Whited, D. Skrtic, B. J. Love, and A. S. Goldstein, "Osteoblast Response to Zirconia-hybridized Pyrophosphatestabilized Amorphous Calcium Phosphate," J. Biomed. Mater Res A., 76 [3] 596-604 (2006). 
4. M. K. Hilal, M. Y. Shareef, K. A. Maher, and R. Van Noort, "Fabrication and Characterization of a Calcium Phosphate/ Zirconia Composite," International Research Journal of Biotechnology, 3 [7] 112-19 (2012).

5. K. Prabakaran, S.Kannan, and S. Rajeswari, "Development and Characterisation of Zirconia and Hydroxyapatite Composites for Orthopaedic Applications," Trends Biomater. Artif. Organs, 18 [2] 114-16 (2005).

6. Y. Yokogawa, Y. Kawamoto, M. Moriyama, T. Suzuki, and S. Kawamura,"Tricalcium Phosphate Coating on Zirconia by Using Calcium Metaphosphate and Tricalcium Phosphate," J. Ceram. Soc. Jpn., 99 [3] 211-14 (1991).

7. Y. Kawamoto, Y. Yokogawa, M. Moriyama, S. Kawamura, and T. Suzuki,"Coating of $\beta$-tricalcium Phosphate on Yttria Partially Stabilized Zirconia by Using Magenesium Meta- phosphate as an Interlayer," J. Ceram. Soc. Jpn., 99 [1] 1922 (1991).

8. I. Sallemi, F. B.Ayed, and J. Bouaziz, "Effect of Fluorapatite Additive on the Mechanical Properties of Tricalcium Phosphate-zirconia Composites," IOP Conf. Ser.: Mater. Sci. Eng., 28012029 1-8 (2012).

9. R. Sultana, J. Yang, and X. Hu, "Deposition of Micro-Porous Hydroxyapatite/Tri-Calcium Phosphate Coating on ZirconiaBased Substrate," J. Am. Ceram. Soc., 95 [4] 1212-15 (2012).

10. A. C. Tas, "Monetite $\left(\mathrm{CaHPO}_{4}\right)$ Synthesis in Ethanol at Room Temperature," J. Am. Ceram. Soc., 92 [12] 2907-12 (2009).

11. A. Lebugle, B. Sallek, and A. T. Tai, "Surface Modification of Monetite in Water at $37^{\circ} \mathrm{C}$ : Characterization by XPS," $J$. Mater. Chem., 9 2511-15 (1999). 